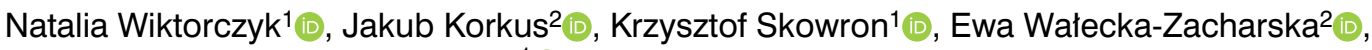
Eugenia Gospodarek-Komkowska ${ }^{1}[0$

${ }^{1}$ Department of Microbiology, Nicolaus Copernicus University in Toruń, Collegium Medicum of L. Rydygier in Bydgoszcz, Poland

2Department of Food Hygiene and Consumer Health, Wroclaw University of Environmental and Life Sciences, Wroclaw, Poland

\title{
The effect of initial sonication on disinfectant efficacy against Listeria monocytogenes biofilm
}

\author{
Corresponding author: \\ Natalia Wiktorczyk, Department \\ of Microbiology, Nicolaus Copernicus \\ University in Toruń, L. Rydygier \\ Collegium Medicum in Bydgoszcz, \\ M. Skłodowskiej-Curie 9 , \\ 85-094 Bydgoszcz, \\ Poland, e-mail: natalia12127@gmail.com
}

Medical Research Journal 2019;

Volume 4, Number 2, 85-88

10.5603/MRJ.a2019.0020

Copyright (C) 2019 Via Medica

ISSN 2451-2591

\begin{abstract}
Background: Listeria monocytogenes is a Gram-positive, foodborne pathogen. Biofilms formed by this bacterium are a serious problem in the food industry. Bacteria in biofilms are much more resistant to cleaning and disinfection agents posing a risk of food recontamination. The aim of this study was the assessment of the influence of initial sonication on disinfectant efficacy, based on QAC, against L. monocytogenes biofilm on the stainless steel.

Methods: The biofilm formed on the stainless steel by the reference strain L. monocytogenes ATCC 19111 was sonicated for 1 and 5 minutes (500W/20kHz/ 100\% amplitude). Then disinfection with quaternary ammonium compounds ( $0.5 \%$ working solution) was applied for 1 and 5 minutes and the number of bacteria recovered from the biofilm was assessed.

Results: It was found that disinfection was more efficient than sonication $(p \leq 0.05)$. However, the combination of sonication and disinfection significantly improved biofilm eradication compared to the use of one of these methods separately $(p \leq 0.05)$. The greatest reduction of bacteria number was achieved after 5 minutes of sonication combined with 5 minutes of disinfection ( $\left.6.42 \mathrm{log} C F U \times \mathrm{cm}^{-2}\right)$, whereas the lowest reduction was observed after 1 minute-sonication (2.03 log CFU $\times \mathrm{cm}^{-2}$ ).

Conclusions: Combination of sonication and disinfection based on quaternary ammonium compounds is an effective method allowing biofilm eradication from the food production surfaces.

Key words: Listeria monocytogenes, biofilm, sonication, disinfectants, quaternary ammonium compounds
\end{abstract}

Med Res J 2019; 4 (2): 85-88

\section{Introduction}

Listeria monocytogenes is a cause of human listeriosis, dangerous especially for pregnant women and an elderly [1]. Since the pathogen is widespread in the environment and food plants it may easily contaminate food. The bacterium was isolated from the variety of food products, including vegetables, fish, meat and dairy products [2].

An important problem in the food industry is recontamination and cross-contamination of food due to biofilm formation ability by L. monocytogenes [2]. The pathogen is able to colonize both abiotic and biotic surfaces [3]. In biofilm, L. monocytogenes is more resistant to disinfectants, UV light, mechanical cleaning and disinfection $[1,5]$. The biofilm structure was shown to be affected by the type of the surface. The biofilms formed on the stainless steel were easier to eradicate compared to biofilms on the polyethene [4]. Effective disinfection is a key factor allowing biofilm eradication and food safety. Quaternary ammonium compounds (QAC) are cationic agents that act by cell membrane disruption. QAC are widely used in hospitals, household and food industry [6]. A serious problem determining bacteria resistance in the biofilm structure is the synthesis of EPS (Extracellular Polymeric Substances) [1, 5]. This structure limits disinfectants penetration so eventually they work in a subinhibitory concentration and may generate disinfectant resistance [7]. The disinfection effectiveness through biofilm disintegration might be increased by an application of enzymatic methods or ultrasounds in a range $20-100 \mathrm{~Hz}[7,8]$. Ultrasound waves of this frequency, in the liquid environment, contribute to cavitation and change of pressure [8]. 
Cavitation may destruct biofilm architecture releasing single bacterial cells that are more susceptible to chemical disinfection [1].

The aim of this study was the assessment of the influence of initial sonication on disinfectant efficacy, based on QAC, against $L$. monocytogenes biofilm on the stainless steel.

\section{Materials and methods}

\section{Materials}

The study was conducted on the reference strain L. monocytogenes ATCC 19111. Stainless steel AISI 304 coupons of $1 \mathrm{~cm} \times 2 \mathrm{~cm}$ and disinfectant based on QAC were used. Coupons were washed in detergent, soaked in $70 \%$ ethanol $(\mathrm{POCH})$, washed with sterile water, dried and autoclaved.

The experiment was carried out in three replications.

\section{Biofilm formation by L. monocytogenes strain}

In a tube of bacterial suspension in Brain Heart Infusion (BHI, Becton Dickinson) (0.5 McFarland scale) a sterile stainless steel coupon was placed and was incubated for 72 hours at $37^{\circ} \mathrm{C}$. The negative control were coupons placed in sterile BHI. Every 24 hours coupons were rinsed with sterile PBS and medium was changed into a fresh $\mathrm{BHI}$. Then coupons were shaken in PBS at $400 \mathrm{rpm}$ for $30 \mathrm{~min}$., 10-fold serial dilutions were made and plated onto Columbia Agar with $5 \%$ of sheep blood (Becton Dickinson). After 24hour incubation at $37^{\circ} \mathrm{C}$, the number of bacteria per $\mathrm{cm}^{2}$ was calculated.

\section{Sonication of L. monocytogenes biofilm on stainless steel coupons}

Coupons with biofilm were placed in a beaker containing $500 \mathrm{ml}$ of sterile PBS. The height of the liquid layer above coupons was $6 \mathrm{~cm}$. The sonicator probe (Sonicator VCX500, Sonics) of $19 \mathrm{~mm}$ diameter was placed in the beaker and the samples were sonicated for 1 and 5 minutes $(500 \mathrm{~W} / 20 \mathrm{kHz} / 100 \%$ amplitude).

\section{Assessment of the effectiveness of disinfection based on QAC}

Coupons after sonication were exposed to $0.5 \%$ QAC disinfectant for 1 and 5 minutes. Subsequently, coupons were neutralized for $2 \mathrm{~min}$ in a solution of Tween 80 (Sigma Aldrich) -10 g; lecithin (Sigma Aldrich) - $1 \mathrm{~g}$; histidine-L (Sigma Aldrich). Finally, coupons were rinsed with a sterile PBS, shaken at $400 \mathrm{rpm}$ for $30 \mathrm{~min}$ and serial 10 -fold dilutions were made and plated onto Columbia Agar with $5 \%$ of sheep blood. After 24-hour incubation at $37^{\circ} \mathrm{C}$, the number of bacteria per $\mathrm{cm}^{2}$ was calculated. The control variant were coupons with formed biofilm, immersed in PBS for 1 and 5 min, treated with QAC, but not sonicated.

\section{Statistical analysis}

Statistical analysis was made using STATISTICA 12 PL software (StatSoft). For each variant mean of 3 replicates was calculated. The statistical differences between the tested variants were evaluated using Tukey post-hoc test at the significance level $\alpha=0.05$.

\section{Results}

The number of bacteria reisolated from biofilm was $7.11 \log \mathrm{CFU} \times \mathrm{cm}^{-2}$. Both sonication and disinfection significantly reduced the number of bacteria, regardless of exposition time. The most efficient biofilm eradication was noted for the combination of sonication and disinfection (Fig. 1). The extension of sonication and disinfection time significantly increased the efficacy of both methods $(p \leq 0.05)$. The greatest reduction of bacteria number was noted after 5-minute sonication, followed by 5-minute disinfection (6.42 log CFU $\times \mathrm{cm}^{-2}$ ). In turn, the lowest reduction was observed after $1 \mathrm{~min}$ ute of sonication (2.03 log CFU $\times \mathrm{cm}^{-2}$ ). It was found that disinfection is more effective than sonication $(p \leq 0.05)$. The reduction of bacteria number after 5-minute sonication and 5-minute disinfection was $2.99 \mathrm{log}$ $\mathrm{CFU} \times \mathrm{cm}^{-2}$ and $4.67 \log \mathrm{CFU} \times \mathrm{cm}^{-2}$, respectively.

\section{Discussion}

The key element ensuring food safety of the consumer is control of cleaning and disinfection in the food-processing plants. An important problem in the food industry, hindering effective cleaning and disinfection, is a biofilm formation. This structure prevents bacteria from adverse environmental factors, e.g. disinfectants and UV light [1, 9]. In the present study sonication and disinfectant based on QAC were used to disrupt $L$. monocytogenes biofilm. It was shown that the combination of 5-minute sonication and QAC exposure resulted in the greatest reduction of the bacteria number (6.42 log CFU $\times \mathrm{cm}^{-2}$ ). Bauman et al. (2009) [10] using sonication for $60 \mathrm{~s}(20 \mathrm{kHz} / 100 \%$ amplitude/ $120 \mathrm{~W})$ observed reduction of $3.8 \mathrm{log}$ CFU/ml. In turn, other researchers [11-13] applying lower power of ultrasounds found the only minimal effect of sonication on biofilm 


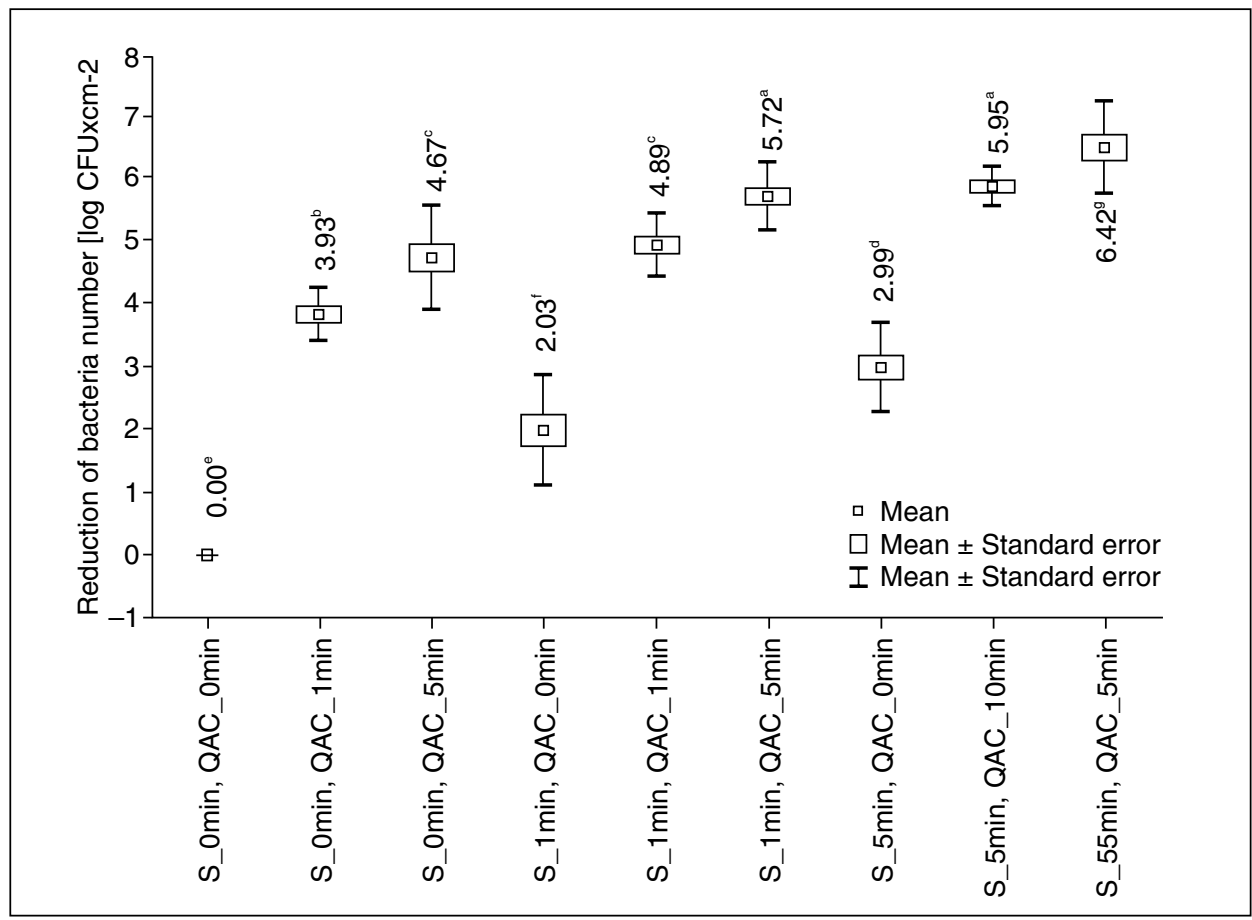

Figure 1. The reduction of bacteria number reisolated from biofilm exposed to sonication and $Q A C[a, b, c, \ldots-$ variables with different letters are statistically different $(p \leq 0.05)]$

eradication on the prosthesis surface. The frequency of ultrasounds also has an impact on biofilm elimination. In our study $20 \mathrm{kHz}$ was applied. Application of ultrasound of this frequency for 30 seconds was found to decrease bacteria number 10 times [1]. Bauman et al. (2009) [10] and Qian et al. (1996) [12] noticed that ultrasounds of $70 \mathrm{kHz}$ frequency better eliminate biofilm than the application of high frequency $(500 \mathrm{kHz})$ ultrasounds. An important aspect is also the efficacy of the disinfectant. We showed that QAC was more effective in biofilm disruption than sonication. Torlak and Sort (2013) [14] using QAC found only $27 \%$ reduction of bacteria number on the plastic surface. However, Romanova et al. (2007) [15] stated that efficient disinfection with QAC requires at least 30 minutes.

In the present stud, the greatest effectiveness in biofilm eradication was noted for the combination of sonication and QAC disinfection. This is in agreement with a study of Torlak and Sert (2013) [14] who demonstrated that regardless of time exposure the best eradication was achieved for the combination of sonication and benzalkonium chloride disinfection. Also, Berrang et al. (2008) [1] contended that sonication might improve disinfectants efficacy against bacterial biofilms. The results of mathematical modelling and conducted experiments revealed that the application of low-frequency ultrasounds boosts biomass transport through biofilm [16-18]. Therefore, it can be assumed that an increase of biomass transport facilitates the transport of disinfectant compound to the biofilm structure [14].

\section{Conclusions}

We have demonstrated that the combination of sonication and disinfection based on QAC the most effectively eliminate biofilm from the stainless steel. Application of sonication might be an easy and cheap method to improve disinfection efficacy leading to $L$. monocytogenes biofilm eradication and food safety.

\section{Conflict of interest}

Authors declare no conflict of interest.

\section{Funding Sources}

This research was financially supported by the Nicolaus Copernicus University with funds from the maintenance of the research potential of the Department of Microbiology (DS-UPB). 


\section{References}

1. Berrang ME, Frank JF, Meinersmann RJ. Effect of chemical sanitizers with and without ultrasonication on Listeria monocytogenes as a biofilm within polyvinyl chloride drain pipes. J Food Prot. 2008; 71(1): 66-69, indexed in Pubmed: 18236664.

2. Belessi CEA, Gounadaki AS, Psomas AN, et al. Efficiency of different sanitation methods on Listeria monocytogenes biofilms formed under various environmental conditions. Int J Food Microbiol. 2011; 145 Suppl 1: S46-S52, doi: 10.1016/j.ijfoodmicro.2010.10.020, indexed in Pubmed: 21093085

3. Gandhi M, Chikindas ML. Listeria: A foodborne pathogen that knows how to survive. Int J Food Microbiol. 2007; 113(1): 1-15, doi: 10.1016/j. ijfoodmicro.2006.07.008, indexed in Pubmed: 17010463.

4. Rodríguez A, McLandsborough LA. Evaluation of the transfer of Listeria monocytogenes from stainless steel and high-density polyethylene to Bologna and American cheese. J Food Prot. 2007; 70(3): 600-606, doi: 10.4315/0362-028x-70.3.600, indexed in Pubmed: 17388047.

5. Chaitiemwong N, Hazeleger WC, Beumer RR. Survival of Listeria monocytogenes on a conveyor belt material with or without antimicrobia additives. Int J Food Microbiol. 2010; 142(1-2): 260-263, doi: 10.1016/ ijfoodmicro.2010.06.021, indexed in Pubmed: 20655607.

6. Møretrø T, Schirmer BCT, Heir E, et al. Tolerance to quaternary ammonium compound disinfectants may enhance growth of Listeria monocytogenes in the food industry. Int J Food Microbiol. 2017: 241: 215-224, doi: 10.1016/j.ijfoodmicro.2016.10.025, indexed in Pubmed: 27810443.

7. Nakamura H, Takakura KI, Sone $\mathrm{Y}$, et al. Biofilm formation and resistance to benzalkonium chloride in Listeria monocytogenes isolated from a fish processing plant. J Food Prot. 2013; 76(7): 1179-1186 doi: 10.4315/0362-028X.JFP-12-225, indexed in Pubmed: 23834792

8. Piyasena P, Mohareb E, McKellar RC. Inactivation of microbes using ultrasound: a review. Int J Food Microbiol. 2003; 87(3): 207-216 doi: 10.1016/s0168-1605(03)00075-8, indexed in Pubmed: 14527793

9. Poimenidou SV Chrysadakou M Tzakoniati A et al. Variability of Listeria monocytogenes strains in biofilm formation on stainless steel and polystyrene materials and resistance to peracetic acid and quaternary ammonium compounds. Int J Food Microbiol. 2016; 237: 164-171, doi: 10.1016/j.ijfoodmicro.2016.08.029, indexed in Pubmed: 27585076.

10. Baumann AR, Martin SE, Feng H. Removal of Listeria monocytogenes biofilms from stainless steel by use of ultrasound and ozone. J Food Prot. 2009; 72(6): 1306-1309, doi: 10.4315/0362-028x-72.6.1306, indexed in Pubmed: 19610346.

11. Peterson R, Pitt $W$. The effect of frequency and power density on the ultrasonically-enhanced killing of biofilm-sequestered Escherichia coli. Colloids and Surfaces B: Biointerfaces. 2000; 17(4): 219-227, doi: 10.1016/s0927-7765(99)00117-4

12. Qian Z, Stoodley P, Pitt WG. Effect of low-intensity ultrasound upon biofilm structure from confocal scanning laser microscopy observation. Biomaterials. 1996; 17(20): 1975-1980, doi: 10.1016/01429612(96)00022-1, indexed in Pubmed: 8894091.

13. Rediske AM, Roeder BL, Brown MK, et al. Ultrasonic enhancement of antibiotic action on Escherichia coli biofilms: an in vivo model. Antimicrob Agents Chemother. 1999; 43(5): 1211-1214, doi: 10.1128/aac.43.5.1211, indexed in Pubmed: 10223938.

14. Torlak E, Sert D. Combined effect of benzalkonium chloride and ultrasound against Listeria monocytogenes biofilm on plastic surface. Lett Appl Microbiol. 2013; 57(3): 220-226, doi: 10.1111/lam.12100, indexed in Pubmed: 23682619.

15. Romanova NA Gawande PV, Brovko LY, et al. Rapid methods to assess sanitizing efficacy of benzalkonium chloride to Listeria monocytogenes biofilms. J Microbiol Methods. 2007; 71(3): 231-237, doi: 10.1016/j. mimet.2007.09.002, indexed in Pubmed: 17928079.

16. Johnson LL. Investigations of the Kinetics and Mechanisms of Ultrasonically Enhanced Killing of Escherichia coli Biofilms. Provo: Brigham Young University Department of Chemical Engineering. ; 1999.

17. Peterson R, Pitt W. The effect of frequency and power density on the ultrasonically-enhanced killing of biofilm-sequestered Escherichia coli. Colloids and Surfaces B: Biointerfaces. 2000; 17(4): 219-227. doi: 10.1016/s0927-7765(99)00117-4

18. Pitt WG, Ross SA. Ultrasound increases the rate of bacterial cell growth. Biotechnol Prog. 2003; 19(3): 1038-1044, doi: 10.1021/bp0340685, indexed in Pubmed: 12790676 